\title{
Seminário mostrou benefícios $\epsilon$ exigências para implantação do BIM na construção
}

\author{
FÁBIO LUÍS PEDROSO - EDITOR* \\ ORCID: https://orcid.org/0000-0002-5848-8710
}

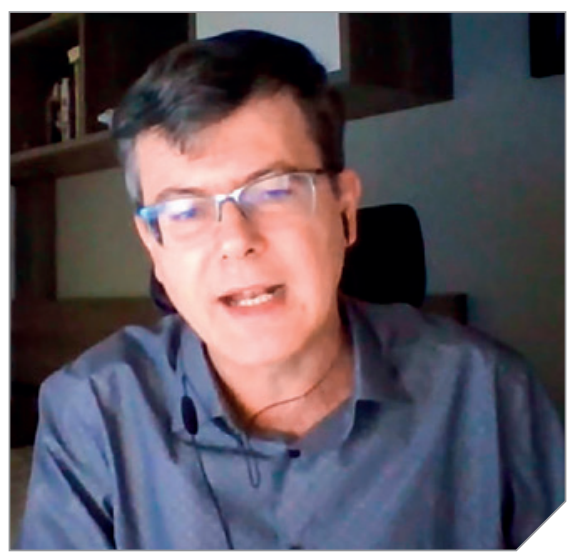

Eng. Rodrigo Koerich, da AltoQi, em momento de sua palestra no Seminário BIM

\section{MUDANÇA NAS TECNOLOGIAS, PROCESSOS E PROFISSIONAIS}

O BIM é um termo muito em voga atualmente na construção civil. Ele se refere a um conjunto de tecnologias, processos e regras que auxiliam os profissionais envolvidos no projeto, construção e operação de uma obra a participar de forma integrada e colaborativa de seu desenvolvimento, gerenciamento e manutenção.

Seus pilares são a tecnologia, as pessoas e os processos. Para o Eng. Koerich, "a tecnologia é o aspecto mais fácil de ser aceito, entendido e incorporado pelo engenheiro de estruturas. Porém, os aspectos mais importantes do BIM - as pessoas e os processos - são os de mais difícil compreensão e incorporação na rotina dos engenheiros projetistas".

Para respaldar sua visão, Koerich teceu a seguinte argumentação. No fluxo tradicional de trabalho em projetos, baseado em AutoCAD, as ferramentas são independentes, de modo que ao projetista, no momento do lançamento estrutural, falta clareza com relação às demais fases de desenvolvimento da obra. Consequentemente, o projetista não tem definidos de antemão todos os requisitos antes de modelar, justamente por não haver interação das equipes interdisciplinares envolvidas com o projeto da obra. "Assim, aparecem as incompatibilidades na execução da obra, que, por vezes, exigem retrabalho", apontou.

O BIM veio para superar esses e outros problemas decorrentes do fluxo tradicional de projetos. "A versão mais recente do software Eberick, programa 


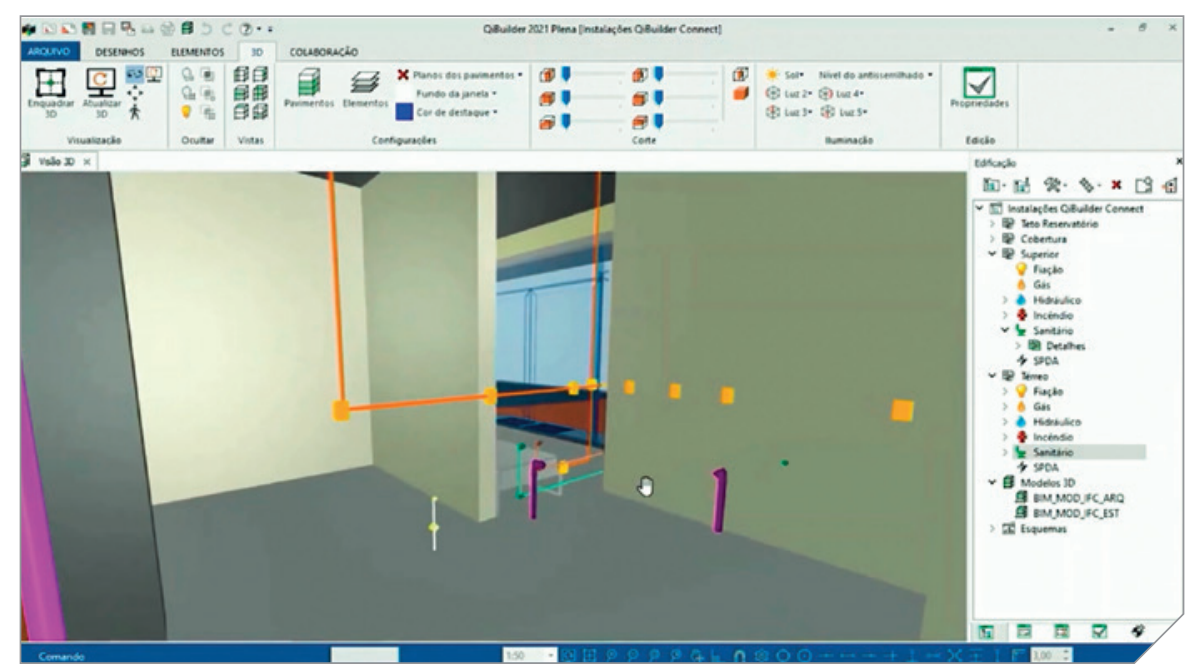

Tela apresentando as instalações sanitárias no QI Builder

de projeto de estruturas da AltoQi, é capaz de integrar na representação todas as disciplinas relacionadas ao projeto - estrutura, armaduras 3D e subsistemas", exemplificou.

É possível também aprimorar modelos arquitetônicos e estruturais de um projeto. Com as ferramentas baseadas em BIM, os modelos estruturais podem ser avaliados à luz da execução e da orçamentação, o que auxilia na tomada de decisão multidisciplinar ainda na fase de projeto.

"A tomada de decisão das fases de planejamento e execução podem também ser antecipadas com o BIM, para a fase de projeto, inclusive com a distribuição do orçamento da obra no tempo, o que é um recurso imprescindível para a boa gestão do empreendimento", destacou Koerich.

Porém, para isto, segundo o palestrante, é necessário que haja uma mudança de mentalidade dos projetistas de estruturas. "De que adianta o projetista de estruturas usar o BIM se as atualizações feitas no projeto não são comunicadas aos demais projetistas ou se não há uma preocupação em resolver as incompatibilidades do projeto surgidas a partir de sua execução?", questionou Koering.

Para ele, não treinar os profissionais e manter os processos tradicionais de trabalho são as razões da queda de produtividade em muitos escritórios de projetos que optaram pelo BIM.

Dentre as mudanças requeridas nos processos de trabalho, Koerich indicou: $>$ o trabalho integrado em nuvem de todas as disciplinas de projetos (arquitetura, estrutura, instalações, orçamento) e de todas as fases do ciclo de vida do projeto, por meio de notas BCF (Building Collaboration Format); no Eberick o lançamento do projeto de arquitetura no IFC, para facilitar as integrações entre os programas das diferentes disciplinas;

$\checkmark$ a vinculação entre os programas e entre os arquivos de projetos da obra, para que cada alteração num modelo seja automaticamente atualizada nos demais modelos vinculados e para que seja possível gerar visualizações integradas;

> a coordenação dos projetos a partir do escritório de projetos de estrutura, por meio de ferramenta de análise de colisão, que retorna lista de incompatibilidades entre vigas, lajes e furações, por exemplo, a partir da qual é possível ao projetista de estrutura fazer análises estruturais e eventuais mudanças no projeto estrutural ou anotações sobre a necessidade de alterações nos projetos de instalações, para a compatibilização;

> a associação do projeto estrutural com o programa de orçamento, possibilitando a geração automática de quantitativos de materiais rastreáveis no projeto e de orçamento desses materiais com base na tabela SINAP;



Tela mostra as interferências $\epsilon$ tre tubos $\epsilon$ vigas $\in m$ projeto $\in m$ andamento 
a documentação do projeto estrutural integrada e atualizada automaticamente.

"A metodologia BIM, mais do que a mudança de tecnologia, exige a mudança de pensar e agir. Para sua perfeita implantação se faz necessário mudar processos de trabalho e se adequar aos diversificados movimentos possibilitados pelas novas tecnologias baseadas no BIM", concluiu Koerich.

\section{NORMALIZAÇÃO DO BIM}

Este enfoque sócio-tecnológico do BIM, que apresenta não apenas seus requisitos físicos e informacionais (hardware e software), mas também os requisitos da interação homem-máquina e da sociedade, foi adotado também pelo palestrante Sérgio Scheer, professor da Universidade Federal do Paraná (UFPR) e presidente da Associação Nacional de Tecnologia no Ambiente Construído (ANTAC).

As políticas, processos e tecnologias integradas no BIM visam ao gerenciamento de informação nas fases de pré-obra (concepção, conceituação, verificação de viabilidade e projeto), obra (construção) e pós-obra (uso e operação, manutenção e monitoramento).

Segundo o Prof. Sheer, "O BIM procura eliminar ou reduzir as perdas de informações que ocorrem entre essas fases por meio da documentação e compartilhamento de informações entre elas. Ele busca também superar a fragmentação entre as equipes envolvidas no projeto e construção por meio da integração e colaboração entre arquitetos, projetistas, instaladores e construtores".

Este gerenciamento de informação na gestão dos processos de projetos e obras com a utilização do BIM é

\section{Histórico ... Qual a relação entre a PAS-1192 e a ISO-19650 ?}
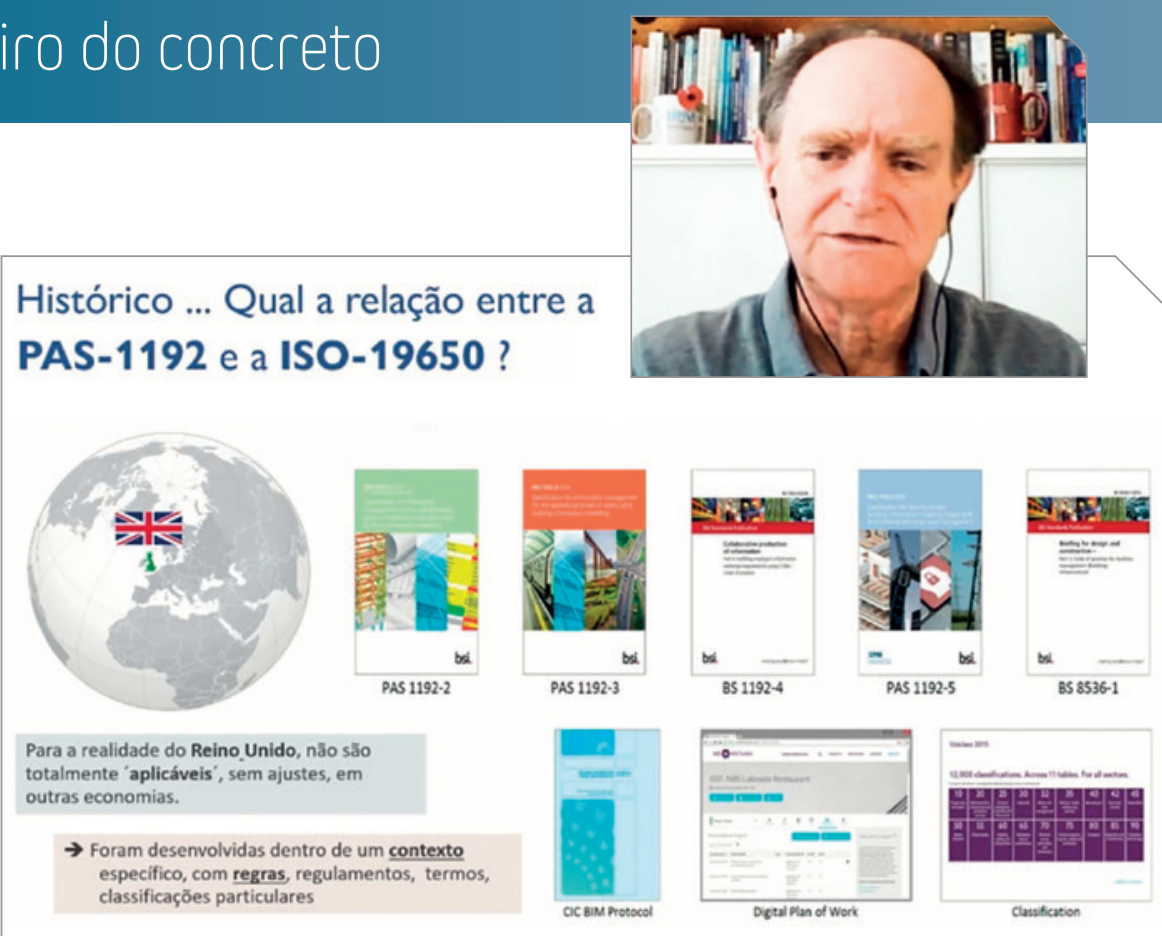

Prof. Sérgio Sche€r, da UfPR, apresentando as relações entre as normas técnicas relacionadas ao BIM

normatizado internacionalmente pela série ISO 19.650, publicada em 2018. Essas normas trazem diretrizes gerais sobre como as informações de um empreendimento de construção devem padronizadamente ser geradas, gerenciadas e entregues ao longo de seu ciclo de vida.

Essas normas lidam com dados geométricos, especificações técnicas e os documentos relativos à concepção, projeto, construção e operação da obra.

As normas requerem das partes interessadas que apenas as informações realmente necessárias para os objetivos e propósitos do projeto e obra sejam disponibilizadas.

Este nível necessário de informação (LOD, do inglês, Level of Development) do BIM é um critério ainda em discussão no mundo. Um aspecto dessa discussão diz respeito ao nível de detalhamento dos elementos vs. o nível de confiança nas informações incorporadas no modelo BIM. "As discussões na $A B N T$ quanto à quantidade, qualidade e granularidade da informação do modelo BIM estão convergindo para quatro critérios - seu propósito, quan- do devem estar disponíveis, quem é o responsável por elas e o que devem trazer", complementou Sheer.

O Prof. Sheer relatou que a norma ISO 19.650 especifica as atividades e os requisitos de informação para cada uma das oito fases de um empreendimento construtivo:

$\checkmark$ termo de referência e licitação são as fases em que se definem os requisitos de informações e sua submissão aos possíveis contratados;

$>$ propostas e contratação são as fases em que se avaliam a competência técnica e os planos iniciais para a entrega da informação;

> mobilização é a fase em que o contratado prepara o plano de entrega da informação;

produção colaborativa da informação é a fase de projeto e construção, no final da qual haverá a entrega do modelo de informação do projeto ou do ativo;

> produção da informação durante a gestão do ativo.

Esse fluxo de informações do empreendimento compõem o ambiente comum de dados, lugar das informações 


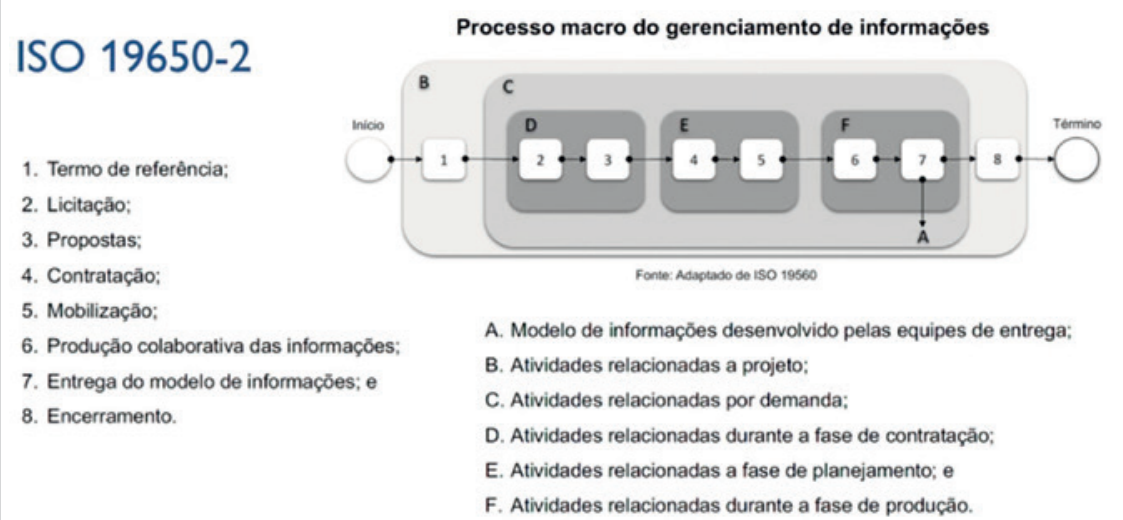

Figura 3 - Gestão da informação durante a fase de entrega dos ativos da NBR 19650-2

Tela mostra as fases de gerenciamento de informações no BIM

disponibilizadas, compartilhadas, revisadas, verificadas, aprovadas e arquivadas entre as partes interessadas, estruturadas por processos e fluxos de trabalho, e viabilizadas por meio de tecnologias da informação.

Por fim, Sheer informou aos congressistas que as duas primeiras normas da ISO 19.650, que tratam de conceitos e princípios no gerenciamento de informações com o BIM, e da fase entrega de ativos, que se refere às fases de projeto e construção, já foram traduzidas e adaptadas para o contexto brasileiro, estando em fase de discussão na Comissão de Estudo Especial de BIM da Associação Brasileira de Normas Técnicas (ABNT). Ele informou também que

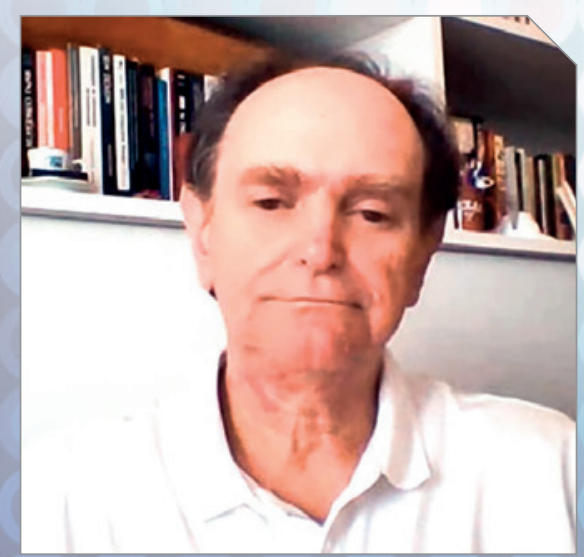

a tradução da terceira norma da série deve ser iniciada em breve.

"Esperamos com este trabalho dar suporte ao contratante na definição dos requisitos de informação para a fase de entrega de um ativo, seja no ramo imobiliário, seja no setor de infraestrutura, para que estruture um ambiente colaborativo adequado para produzir, compartilhar e validar informação de forma efetiva e eficiente", finalizou Sheer.

Questionado, na sessão de debates, pelo moderador Luís César De Luca, assessor da diretoria de eventos do IBRACON, sobre como o conhecimento e práticas do BIM estão organizados no Brasil, o Prof. Sheer respondeu que existem atualmente alguns

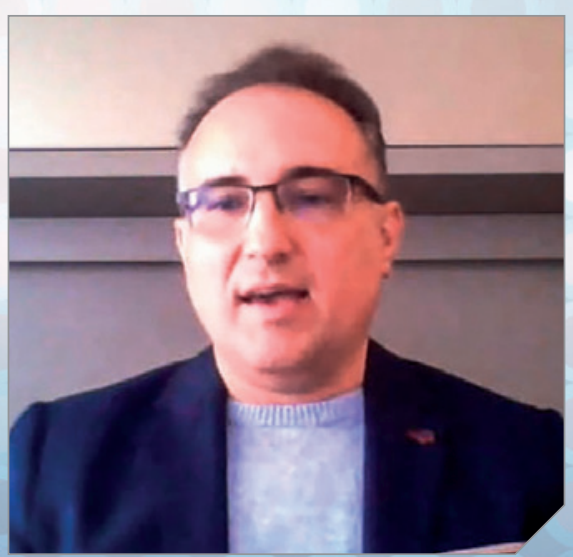

manuais de boas práticas de uso do BIM, que adaptaram os conhecimentos e práticas do BIM no mundo ao contexto das normas e procedimentos nacionais, desenvolvidos por entidades técnicas e órgãos estaduais e federais. "Além disso, existe o BIM Fórum Brasil, lançado em setembro de 2020 e que busca harmonizar e coordenar os esforços na área de BIM no país", complementou.

\section{BENEFÍCIOS DO USO DO BIM NO EXÉRCITO BRASILEIRO}

Os benefícios e vantagens da implantação do BIM no Exército Brasileiro foi o tema da palestra da tenente Fernanda Louise Monteiro Brocardo, arquiteta e urbanista da Comissão Regional de Obras da $5^{a}$ Região (Paraná e Santa Catarina) do Exército Brasileiro e membro do Comitê de Disseminação do BIM no Sistema de Obras Militares.

Ela reforçou que a implantação do BIM envolve a integração de tecnologia (escolha dos softwares), pessoas (capacitação de pessoal) e processos (fluxos de trabalhos) para garantir a colaboração eficiente, a integridade das informações, a documentação inteligente, o acesso facilitado aos dados da construção, a alta qualidade dos

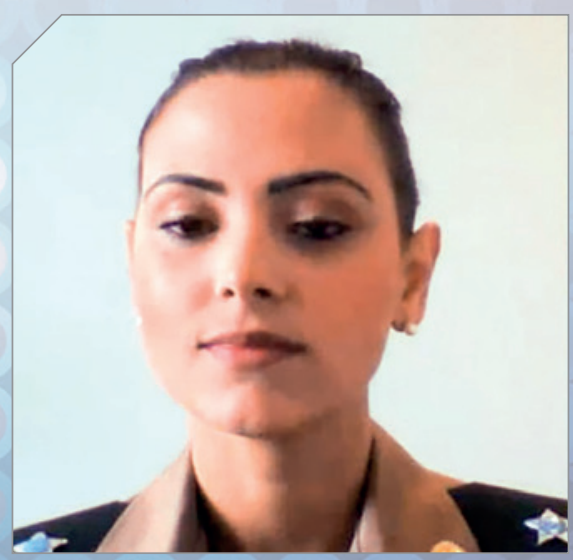

Prof. Luís César De Lucca (ao centro) mediando a sessão de debates com os palestrantes Sérgio Scheer e Fernanda Brocardo 
projetos e o planejamento e coordenação da construção e gestão dos ativos.

O Exército Brasileiro é responsável por todo o ciclo de vida de uma construção militar, desde sua solicitação e planejamento, passando pelo projeto, licitação e fiscalização, até sua manutenção e demolição. Atualmente, a instituição gerencia 88 mil edificações em 12 Regiões Militares, por meio do Sistema Unificado do Processo de Obras (OPUS), primeira ferramenta baseada em BIM utilizada pelo Exército.

O OPUS centraliza todas as in- formações referentes às obras do Exército e possibilita que se faça o planejamento do Estado-Maior, a identificação das obras necessárias para atingir os objetivos estratégicos, o plano diretor das organizações militares, a previsão de recurso orçamentário, a gestão da elaboração de projetos e orçamentos, o controle da licitação, a contratação da obra e a fiscalização. "O Exército não executa as obras, mas é responsável por suas licitações e fiscalização", informou a tenente Brocardo.

A tenente destacou as vantagens trazidas pelo sistema: facilitar a rela-

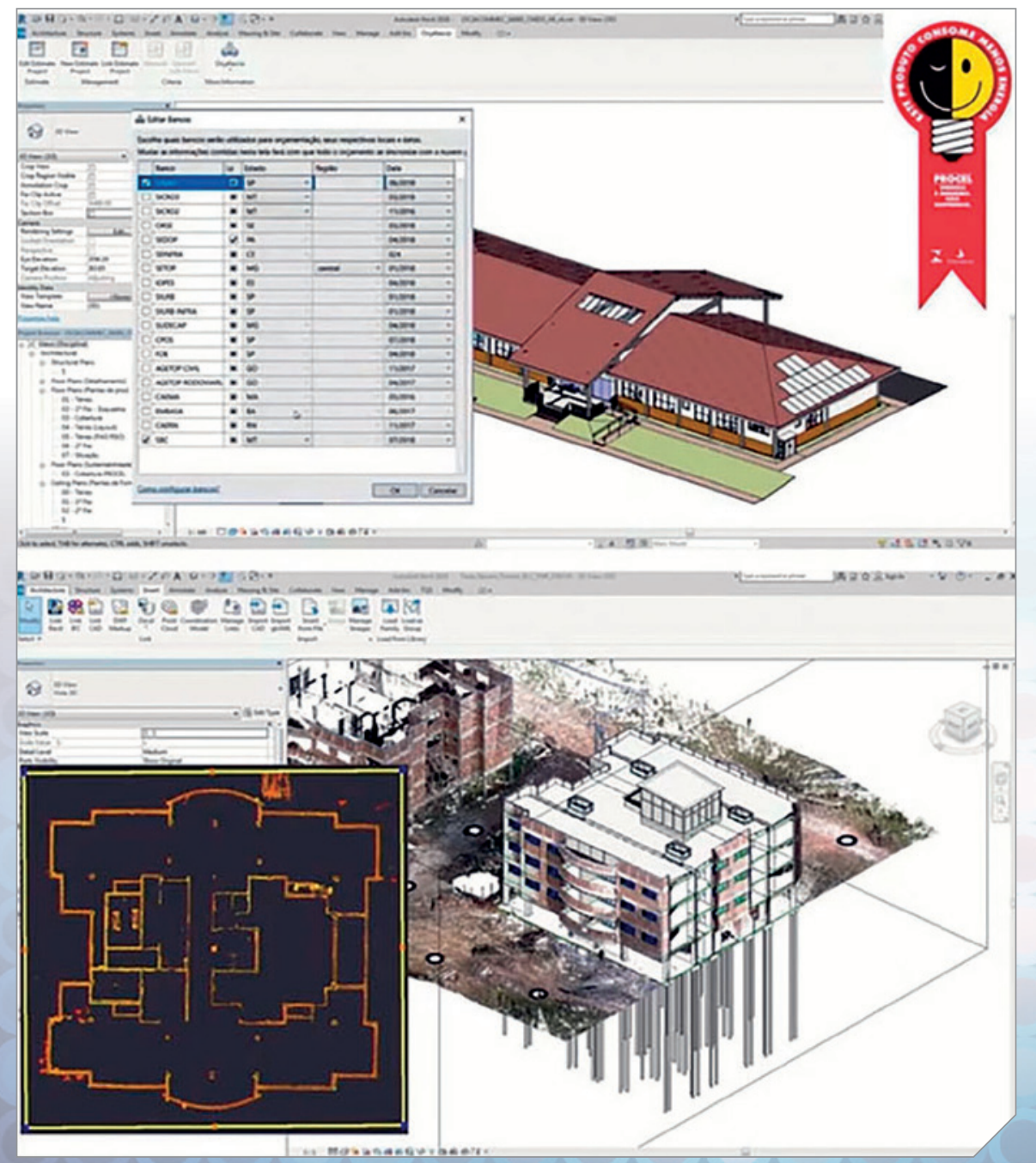

Interfaces BIM do Sistema do Exército Brasileiro para gerenciamento de informações na construção ção entre demanda e planejamento; acompanhar os ativos; padronizar processos (com consequente redução dos erros e ganhos de produtividade); mensurar espaços, materiais e elementos construtivos; cooperar interdisciplinarmente; analisar a edificação quanto à eficiência energética, sustentabilidade e segurança; e facilitar a implantação de políticas públicas. Apontou também algumas desvantagens: alto custo dos softwares, curva de aprendizagem elevada (ocasionando resistência de membros da equipe por exigir mudanças de processos), falta de interoperabilidade entre os softwares de diferentes disciplinas e dificuldade de adequação do software estrangeiro às normas nacionais.

O decreto 10.306 de abril de 2020 lançou o Estratégia BIM BR - Estratégia Nacional de Disseminação do BIM, estipulando metas para uso do BIM pelos órgãos públicos federais, entre elas: fazer todos os projetos estratégicos em BIM a partir de 2021; utilizar modelos BIM na execução das obras a partir de 2024; e usar modelo BIM para gestão e manutenção das edificações a partir de 2028. "O objetivo da Estratégia BIM BR é aumentar a produtividade das empresas brasileiras em $10 \%$, reduzir os custos da construção em 9,7\% e aumentar o PIB da construção civil em 28,9\% até 2028", complementou Brocardo.

Com vistas a se adequar ao decreto, a Comissão Regional de Obras da $5^{\text {a }}$ Região do Exército desenvolveu um projeto para organizar seus processos colaborativos de uso do BIM e promover a implantação de melhorias na gestão dos projetos de obras, 
desde o estudo preliminar, passando pelos projetos básicos e executivos, até a licitação e o as built, bem como a utilização futura dos modelos em todo o ciclo de vida das edificações sob sua responsabilidade.

A tenente informou que este projeto teve como resultados a elaboração de Guias de Boas Práticas em BIM para as Comissões de Obras, a capacitação das equipes para trabalhar com o BIM, a compatibilidade e integração entre os projetos (BIM Collaboration Format), a antecipação de erros construtivos (BIM 4D), o uso de plugins para extração automática de quantitativos para orçamentação (BIM 5D), o uso de modelos de análise de eficiência energética (BIM 6D) e uso de modelos As built para operação e manutenção de edificações (BIM 7D).

"Os resultados gerados a partir dos dados coletados pelo sistema OPUS mostraram que a adoção do BIM pelo Exército Brasileiro em suas obras melhorou a eficiência na gestão das informações produzidas em todas as fases dessas obras e implicou uma redução significativa de aditivos nos contratos", respondeu a tenente Brocardo ao questionamento do mediador com relação à comparação entre obras executadas com e sem BIM.

\section{BENEFÍCIOS DO BIM PARA PROJETOS ESTRUTURAIS}

O Eng. Dionísio Augusto Americano de Neves e Souza, diretor da Proger Engenharia, abriu sua participação no II Seminário BIM contando que o preço menor na aquisição da licença do AutoCad foi sua motivação inicial para adquirir o Revit. Por sua

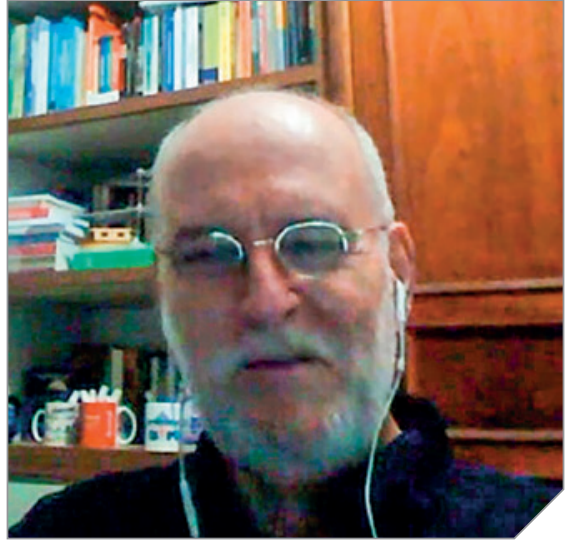

Eng. Dionísio Americano $\in \mathrm{m}$ momento de sua palestra no II Seminário BIM

vez, sua curiosidade para aprender a usar a nova ferramenta foi estimulada pela qualidade final de apresentação dos trabalhos de conclusão de curso de suas turmas na disciplina de estruturas.

"Passei a estudar como a nova tecnologia poderia melhorar os processos e a apresentação de meus projetos de lançamento estrutural e conclui que o plano de desenvolvimento estrutural a ser concebido necessita da visualização da concepção de nível superior (arquitetônico) - onde estão as cargas atuantes na estrutura - e inferior - onde as peças estruturais serão posicionadas. Em razão disso, o ganho em visualização 3D com recursos adicionais substitui, com enorme vantagem, a antiga estratégia de transparência dos vegetais na prancheta e as camadas do CAD", concluiu Dionísio Americano a respeito do uso do Revit.

Ele exemplificou esses ganhos em sua palestra. O projeto estrutural do complexo hospitalar de Casca Dura, no Rio de Janeiro, se baseou na topografia do terreno com curvas de nível, obtida por meio de aplicativos web e cuja modelagem foi feita por linguagem de programação
Dynamo, nativa do Revit. Os detaIhamentos estruturais dos cortes e vistas das plantas de uma edificação com subsolo enterrado foram gerados automaticamente no modelo BIM. A construção virtual de um shopping center em Teixeira de Freitas, na Bahia, com estrutura mista, possibilitou simular aspectos estruturais para tomada de decisões na fase de projeto.

"Com relação à orçamentação no BIM, a tipologia de lançamento estrutural para um determinado escritório de arquitetura possibilita obter um orçamento prévio para a obra antes do modelo estrutural, a partir de índices criados com base em projetos anteriores. A diferença entre este orçamento baseado nos índices e o orçamento real baseado nos dados do modelo vai depender da quantidade de projetos já feitos com a tipologia para aquele cliente", ilustrou Dionísio Americano em relação à interação da disciplina de estruturas com as demais no modelo BIM.

Ele estendeu esta assertividade do BIM no projeto para outras disciplinas, como o planejamento da execução da obra, exemplificando que um setor da obra a ser executado pode ser subdividido na etapa de projeto, em razão do grande volume de concreto a ser lançado. "Com o BIM, isto passa a ser uma decisão de projeto, porque as vigas serão armadas de outra maneira, já que com mais uma junta de dilatação o planejamento ficará melhor", explicou.

A interligação entre arquitetura e estrutura, principalmente em projetos em que a estrutura faz parte do partido arquitetônico foi exemplificado para diferentes fluxos de trabalho: 


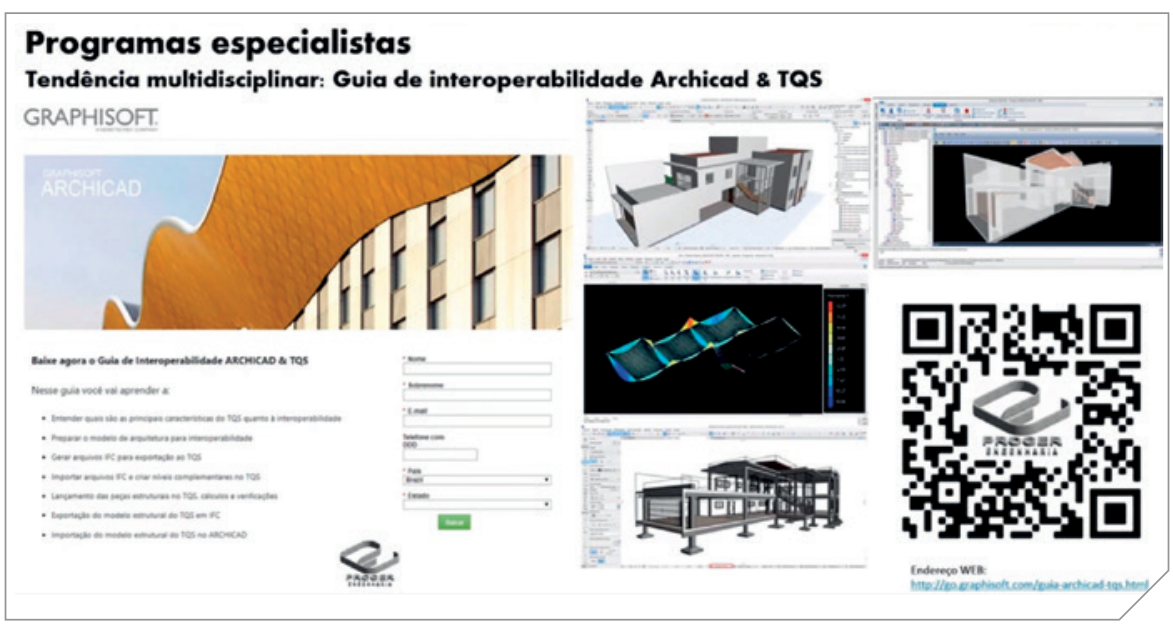

Tela apresenta o Guia de interoperabilidade Archicad $\epsilon$ TQS

Revit-TQS-Revit: projetos de arquitetura e lançamento estrutural, feitos no Revit, são enviados para o TQS, que valida as peças estruturais lançadas e efetua as análises e cálculos estruturais, com solução automática das possíveis interferências entre o Revit e o TQS; por fim, o modelo estrutural volta para o Revit, que gera automaticamente as plantas de fôrmas;

> Archicad-TQS-Archicad: modelo da arquitetura feito no Archicad é enviado ao TQS, que estabelece automaticamente os planos de desenvolvimento estrutural, posicionando as plantas arquitetônicas por pavimento; em seguida, o lançamento estrutural é executado no TQS, que valida o modelo e os cálculos; por fim, o modelo estrutural, com exportações das armações, é enviado novamente ao Archicad, para gerar documentações - nas versões mais recentes, o Archicad cria o modelo analítico, que pode ser aproveitado em programas de elementos finitos, para análise estrutural.

"O importante é utilizar as características de cada programa para trazer organização, clareza e eficiência no fluxo de trabalho do escritório de projeto estrutural”, finalizou Dionísio.

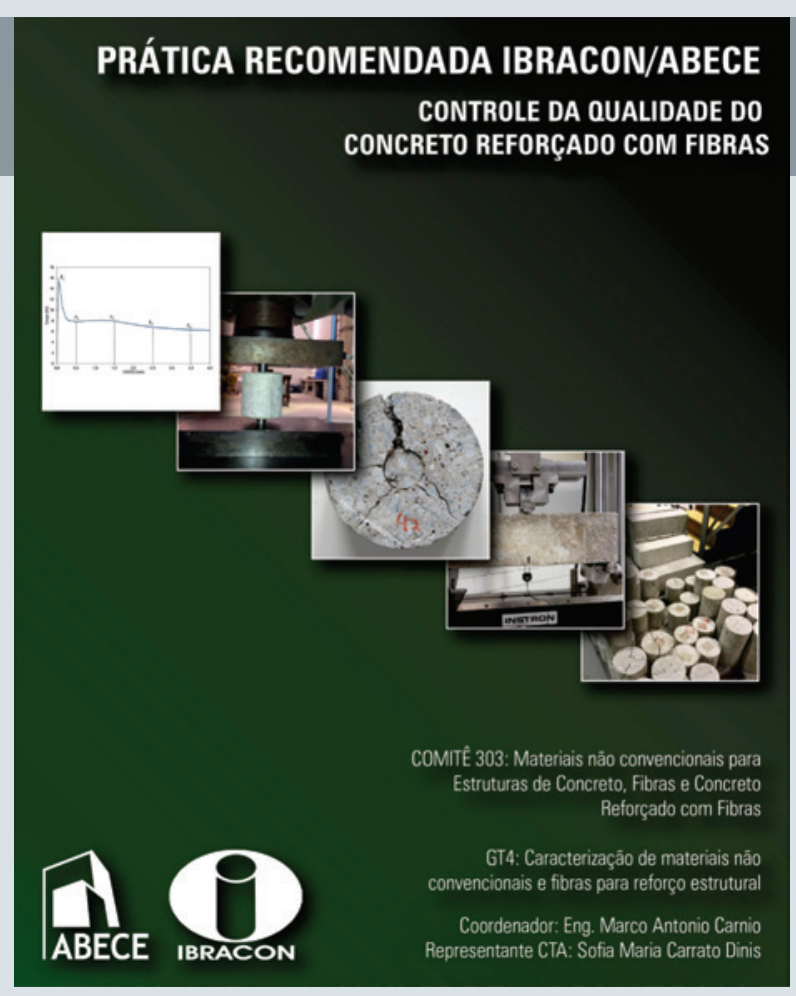

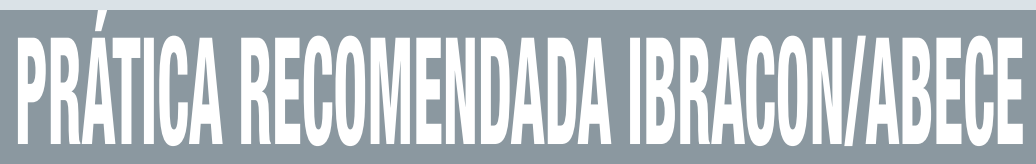

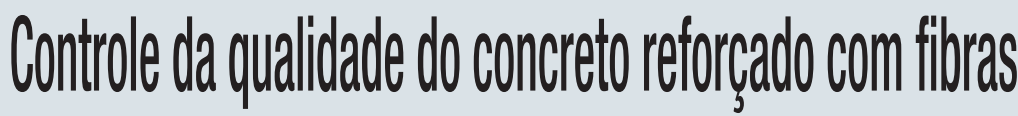

Elaborada pelo CT 303 - Comitê Técnico IBRACON/ABECE sobre Uso de Materiais não Convencionais para Estruturas de Concreto, Fibras e Concreto Reforçado com Fibras, a Prática Recomendada "Controle da qualidade do concreto reforçado com fibras" indica métodos de ensaios para o controle da qualidade do CRF utilizado em estruturas de concreto reforçado com fibras e estruturas de concreto reforçado com fibras em conjunto com armaduras.

A Prática Recomendada aplica-se tanto a estruturas de placas apoiadas em meio elástico quanto a estruturas sem interação com o meio elástico.

A Q U I S I Ç Ã 0
www.ibracon.org.br (Loja Virtual)

\section{DADOS TÉCNICOS}

ISBN: 978-85-98576-30-5

Edição: $1^{\mathrm{a}}$ edição

Formato: eletrônico

Páginas: 31

Acabamento: digital

Ano da publicação: 2017

Coordenador: Eng. Marco Antonio Carnio

Patrocínio
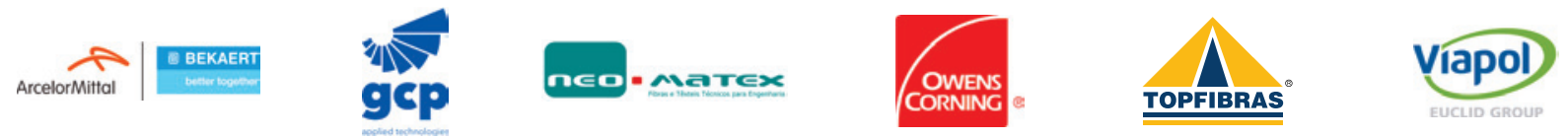